\title{
塔里木盆地风积物表土磁学特征及其与物源物质、 气候条件的关系
}

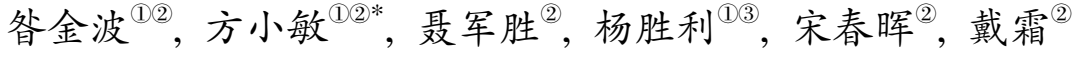 \\ (1) 中国科学院青藏高原研究所大陆碰撞与高原隆升重点实验室, 北京 100085; \\ (2) 兰州大学西部环境教育部重点实验室, 兰州 730000; \\ (3) 南京师范大学地理科学学院, 南京 210046 \\ *联系人, E-mail: fangxm@itpcas.ac.cn \\ 2010-05-04 收稿, 2010-08-23 接受 \\ 国家自然科学基金(41021001, 40972122, 40920114001)和中国科学院知识创新工程重要方向项目(KZCX2-YW-Q09-04)资助
}

\begin{abstract}
摘要 黄土高原地区地表土壤磁化率与气候的温湿程度(温度和降水)呈明显的正相关关系, 目 前成壤过程中形成的细颗粒软磁性矿物被认为是导致土壤磁化率增加的主要原因, 磁化率作 为一个夏季风代用指标在该区得到广泛应用。但相对于黄土高原地区比较成熟的岩石磁学研 究来说, 目前对主要由西风带所控制的塔里木盆地及其周边地区的表土岩石磁学性质的研究 还相对较少，对控制该区表土岩石磁学性质的主要原因也还不是十分清楚。为进一步理解不同 气候、不同环境条件下土壤磁化率与气候的关系, 对塔里木盆地及其南缘 49 个风尘堆积表土 样品进行了详细的岩石磁学和粒度分析. 结果表明, 研究区表土样品的岩石磁学性质主要由来 自源区的粗颗粒软磁性矿物所控制, 成壤作用形成的细颗粒磁性矿物对其影响非常有限. 其 中, 沙漠样品的磁化率和饱和等温剩磁都表现为最低值, 主要由富含软磁性矿物的颗粒含量较 少所造成. 亚砂土和黄土样品的磁化率和饱和等温剩磁均高于沙漠样品, 且随着海拔的升高有 明显减小的趋势, 来自源区的粗颗粒软磁性矿物的含量是导致这种变化的主要原因.
\end{abstract}

黄土高原上堆积的黄土-古土壤序列以及下伏的 红黏土序列, 被认为是晚新生代以来古气候信息最 为丰富的陆相沉积物. 通过对现代地表土壤磁化率 与气候条件的相关关系研究, 发现黄土高原地区表 土样品的磁化率值与气候的温湿程度 (温度和降水) 呈明显的正相关关系，成壤过程中形成的细颗粒的 软磁性矿物被认为是导致土壤磁化率增加的主要原 因 ${ }^{[1 \sim 8]}$, 用黄土-古土壤磁化率可以定量的恢复黄土高 原地区的古降雨量 ${ }^{[9 \sim 14]}$.

然而, 最近的一些研究表明, 土壤磁化率值与古 气候的关系在黄土高原以外的一些地区则要复杂的 多. 如阿拉斯加以及西伯利亚的黄土古土壤磁化率 不仅受控于冰期间冰期风力大小变化的影响 ${ }^{[15 ~ 18]}$,
成壤过程中发生的磁性矿物的溶解对磁化率的变化 也有重要的影响 ${ }^{[19,20]}$. 此外, 在中国西部、北部靠近 沙漠边缘的一些地区, 黄土的磁化率强度则主要由 物源物质的磁学性质所控制 ${ }^{[21,22]}$, 气候条件对其影 响微弱. 因此, 了解现在不同气候、不同环境下表层 土壤磁化率的分布特征以及控制因子, 将有利于进 一步加深我们对磁化率值与古气候相互关系的认识.

塔里木盆地位于我国内陆极端干旱区, 主要为 西风带所控制, 受东亚季风的影响较小. 在塔里木盆 地和昆仑山之间, 沉积物明显地分异成 4 个地带 ${ }^{[23]}$, 即沙漠(1400 m 以下)、戈壁(1400 2000 m)、亚砂土 (2000 2500 m) 和黄土 $(2500 \sim 4500 \mathrm{~m})$. 其中, 除戈壁 外, 其他 3 类均为风力沉积作用所形成. 由于随着海 
拔和沉积相带的变化, 这 3 类风力堆积物对应着不同 的气候条件(温度和降水), 因此是探讨磁化率与气候 条件、物源物质相互关系的理想材料. 为此, 本文对 沙漠带(11 块样品)、亚砂土带(8 块样品)和黄土带(30 块样品)采集的 49 块表土样品进行了详细的岩石磁学 和粒度分析, 并对控制其磁学性质的主要原因做了 初步分析.

\section{1 样品与方法}

表土样品根据海拔以 $20 \sim 100 \mathrm{~m}$ 的间隔进行取样, 跨越沙漠、亚砂土和黄土 3 个沉积相带(图 1), 共获 得样品 49 块. 采样时尽量选择远离耕地和城镇村庄、 没有受人类干扰的地区, 采样深度不超过地表 $5 \mathrm{~cm}$. 49 块表土样品随着海拔的升高对应着不同的气候条 件. 其中, 沙漠样品对应的气温最高, 降水最少, 其 年降雨量不足 $50 \mathrm{~mm}$; 而海拔 $3500 \mathrm{~m}$ 以上的黄土样 品, 年降雨量则可以达到 $400 \mathrm{~mm}$ 以上 $^{[24]}$.

粒度样品经依次加人 $10 \mathrm{~mL} 10 \%$ 双氧水、 $10 \mathrm{~mL}$ $10 \%$ 盐酸除去有机质和碳酸盐后, 再加人 $10 \mathrm{~mL}$ $3.6 \%$ 的 $\left(\mathrm{NaPO}_{3}\right)_{6}$ 溶液, 最终在超声波振荡 $10 \mathrm{~min}$ 后 用 Microtrac S3500 激光粒度仪进行测试. 低频(470 $\mathrm{Hz}$ )磁化率 $(\chi)$ 和高频 $(4700 \mathrm{~Hz}$ )磁化率用 BartingtonMS 2 型磁化率仪进行测量, 并计算频率磁化率 $\left(\chi_{\mathrm{fd}}=\chi_{470 \mathrm{~Hz}}-\chi_{4700 \mathrm{~Hz}}\right)$ 以及频率磁化率百分比 $\left(\chi_{\mathrm{fd}} \%\right.$ $\left.=\left(\chi_{470 \mathrm{~Hz}}-\chi_{4700 \mathrm{~Hz}}\right) / \chi_{470 \mathrm{~Hz}} \times 100 \%\right)$. 样品的等温剩磁 $(\mathrm{IRM})$ 和饱和等温剩磁 $\left(\mathrm{SIRM}=\mathrm{IRM}_{1000 \mathrm{mT}}\right.$ ) 用 ASC 磁 化仪和 Molspin Minispin 小旋转磁力仪获得, 之后将 样品置于 $300 \mathrm{mT}$ 反向磁场中磁化, 得到 $\mathrm{IRM}_{-300 \mathrm{mT}}$,
并定义 $S$ 比值 $\left(=-\mathrm{IRM}_{-300 \mathrm{mT}} / \mathrm{SIRM}\right)$. 此外, 我们还用 VFTB(variable field transition balance)测量仪对部分 样品的热磁(居里点)曲线和磁滞回线进行了测量. 以 上实验除粒度在中国科学院青藏高原研究所完成外, 其余实验均在兰州大学西部环境教育部重点实验室 完成.

\section{2 结果}

\section{1 磁化率、饱和等温剩磁以及粒度变化特征}

塔里木盆地及其南缘风积物的表土磁化率值相 对较低, 在 $1.5 \times 10^{-7} \sim 4.0 \times 10^{-7} \mathrm{~m}^{3} / \mathrm{kg}$ 之间(图 2). 其中 沙漠样品的磁化率变化较小, 磁化率值也最低, 多数 分布在 $1.5 \times 10^{-7} \mathrm{~m}^{3} / \mathrm{kg}$ 附近. 而亚砂土和黄土样品随 着海拔的增高, 磁化率值呈逐步减小的趋势. 同低频 磁化率这种有规律的变化趋势相比, 频率磁化率以 及频率磁化率百分比的波动不是很明显, 且值较低, 分别分布于 $0 \sim 0.2 \times 10^{-7} \mathrm{~m}^{3} / \mathrm{kg}$ 和 $0 \sim 5 \%$ 之间.

吕厚远等人 ${ }^{[9]}$ 曾对中国不同地区表土磁化率与 温度和降水量的关系进行了统计分析, 发现塔里木 盆地及其周围地区的表层土壤磁化率随年均温、年均 降水量的变化几乎没有什么趋势. 由于成壤作用主 要受温度以及降水量的多少所控制, 他们的研究似 乎暗示成壤作用形成的细颗粒磁性矿物并不是控制 塔里木盆地风积物表土磁化率变化的最主要的原因. 而塔里木盆地风积物表土磁化率与频率磁化率以及 频率磁化率百分比所表现出的这种极弱的相关关系 也再次印证了这种可能性.

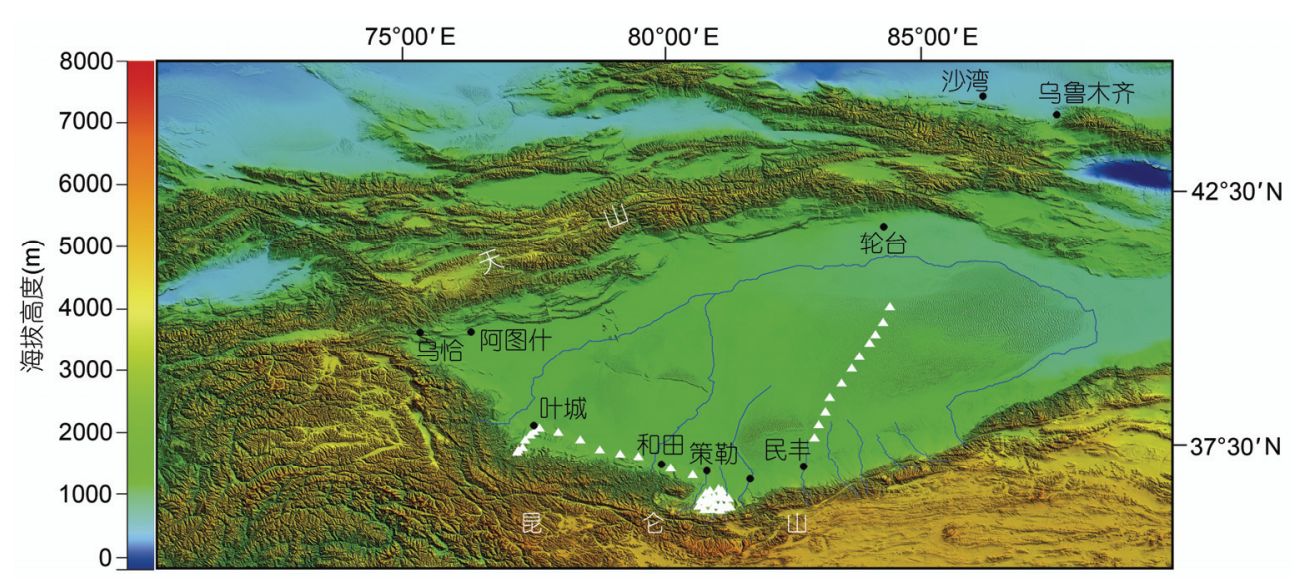

图 1 塔里木盆地 DEM 图及表土采样位置 $\Delta$ 代表取样点 


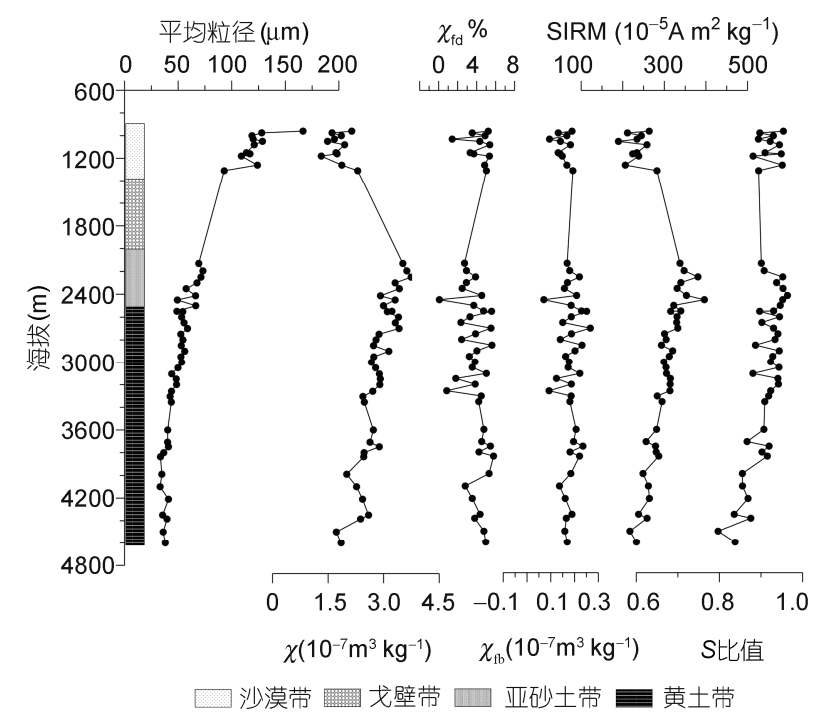

图 2 表土样品粒度及各岩石磁学参数随海拔和沉积相带的 变化

饱和等温剩磁(SIRM)不受顺磁性和抗磁性物质 的影响, 主要由亚铁磁性矿物和不完整反铁磁性矿 物所贡献 ${ }^{[25,26]}$. 饱和等温剩磁变化趋势同磁化率十 分相似(图 2). 两者都在沙漠中呈现最低值, 而在亚 砂土和黄土中随海拔的升高呈逐渐减小的趋势, 这 进一步证实了随着沉积相带和海拔的变化, 磁化率 所反映的样品磁学性质的规律性变化.

表土样品的粒度组成随海拔的增高呈明显的减 小趋势 (图 2,3(a)). 其中沙漠样品的平均粒径最粗, 基本在 $100 \mu \mathrm{m}$ 以上. 而亚砂土和黄土样品的平均粒 径则明显变小, 分布于 30 70 $\mu \mathrm{m}$ 之间. 相关分析表 明(图 3(a), (b)), 表土样品的平均粒径与海拔高度呈 极高的负相关 $\left(R^{2}=0.96\right)$, 并且亚砂土和黄土样品的
粒度变化趋势同磁化率波动形式十分相似, 两者都 随海拔的升高而呈逐渐减少的趋势, 似乎暗示风力 分选作用造成的粉尘物质的组成差异可能在某种程 度上是控制亚砂土和黄土样品磁化率信号强弱的重 要原因.

\section{2 热磁曲线}

热磁曲线不仅能够揭示样品中主要载磁矿物的 种类, 而且还能够较客观地反映出主要磁性矿物在 加热过程中发生的相变 ${ }^{[26]}$. 本次研究发现(图 4), 随 着海拔的升高, 表土样品的热磁曲线可以明显的分 成 3 类. (1) 沙漠样品: 冷却曲线高于加热曲线. 磁化 强度在 $580^{\circ} \mathrm{C}$ 附近几乎降低到零, 说明样品中的磁性 矿物以磁铁矿为主. 此外, 冷却过程中, 随着温度的 降低, 磁化强度明显升高, 表明样品中含有的一些弱 磁性矿物 (如铁的硫化物) 在加热过程中发生了转变, 形成了强磁性的磁铁矿 (居里点 $580^{\circ} \mathrm{C}$ ) ${ }^{[19,20]}$. (2) $2100 \sim$ $3300 \mathrm{~m}$ 之间的亚砂土和黄土样品: 冷却曲线位于加 热曲线的下方. 磁化强度在 $580^{\circ} \mathrm{C}$ 附近发生有明显的 下降, 表明样品中含有大量的磁铁矿. 此外, 磁化强 度在 $300 \sim 450^{\circ} \mathrm{C}$ 间明显的减少以及实验前后样品饱 和磁化强度的显著降低, 表明样品中还含有一定量 的不稳定矿物磁赤铁矿 ${ }^{[19,20]}$. (3) $3300 \mathrm{~m}$ 以上的黄土 沉积: 冷却曲线远高于加热曲线. 冷却后样品的磁化 强度升高了 $3 \sim 5$ 倍, 并且加热曲线在 $500^{\circ} \mathrm{C}$ 左右磁化 强度有一明显的峰值. 这些特征一方面说明加热过 程中有大量新的亚铁磁性矿物的生成, 同时, 与第一 类热磁曲线相比, 还可能表明样品中含有的弱磁性 矿物的种类和含量都发生了明显的变化 ${ }^{[20]}$. 此外, 磁化强度在 $580^{\circ} \mathrm{C}$ 时的急剧降低, 表明同前两类样品
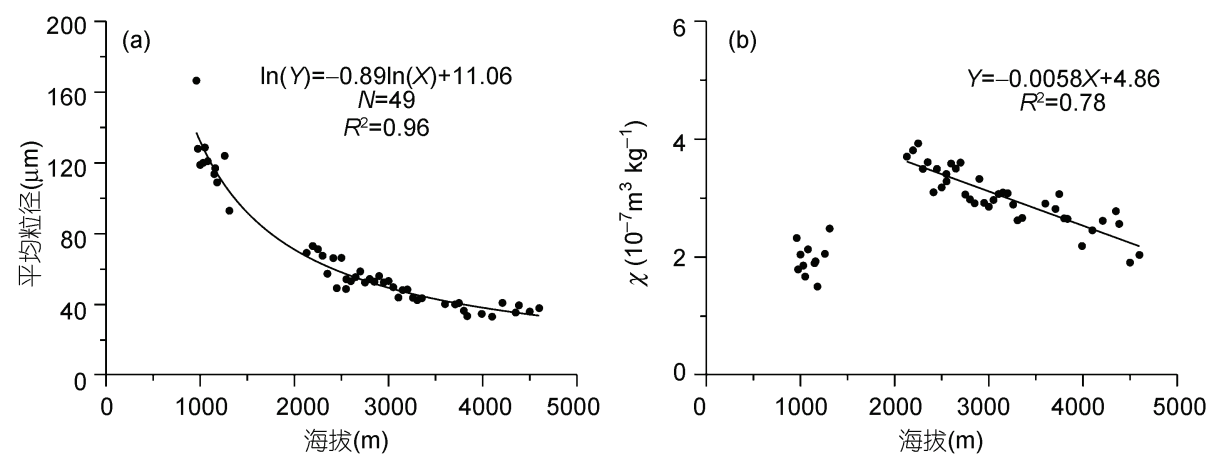

图 3 表土样品粒度(a)和磁化率(b)与海拔高度的相关性分析 

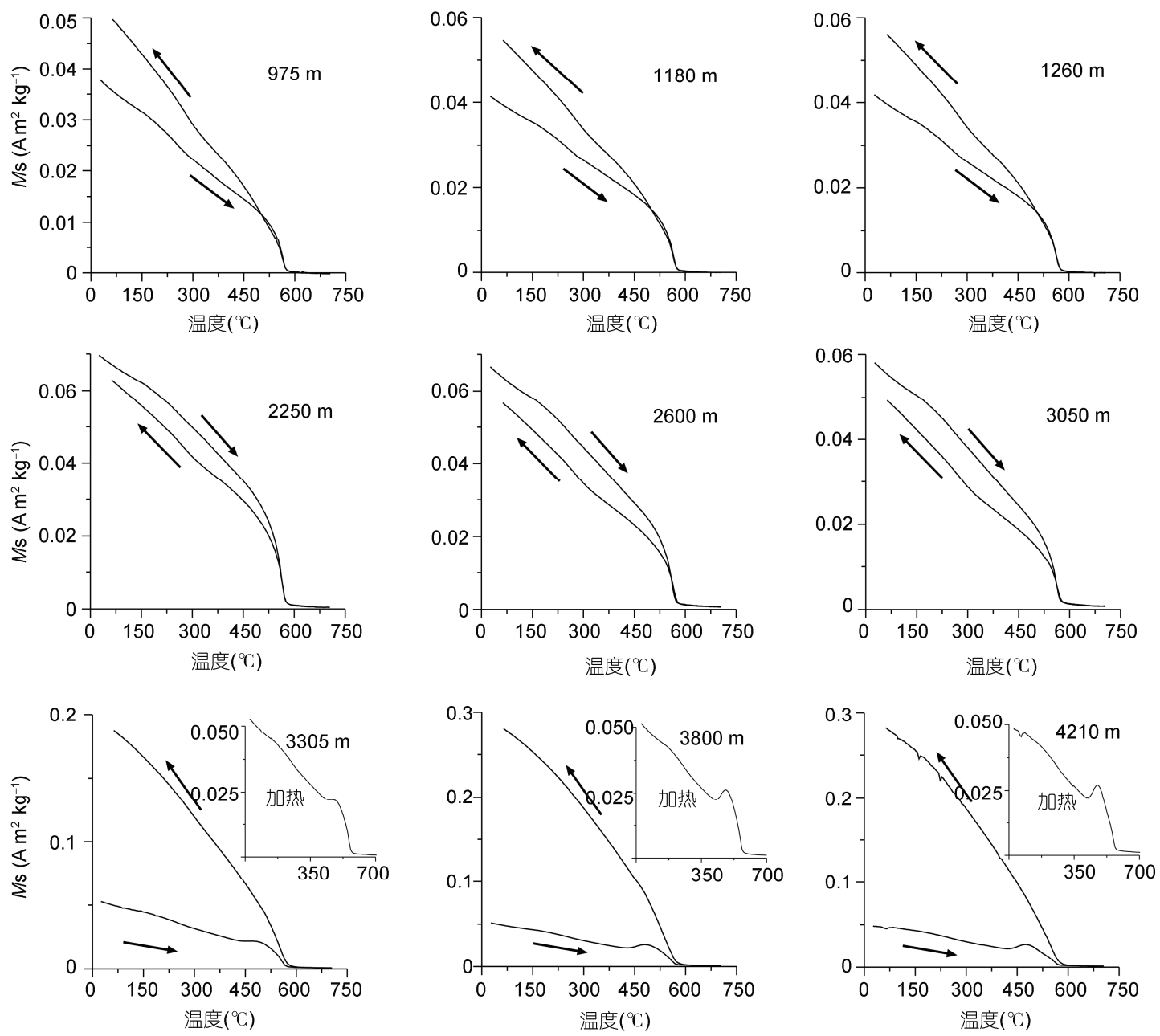

图 4 代表性样品的热磁曲线图 所加磁场强度为 $1 \mathrm{~T}$

一样, $3300 \mathrm{~m}$ 以上的黄土沉积中的磁性矿物同样以 磁铁矿为主.

\section{3 磁滞回线}

磁滞回线能够提供关于磁性矿物类型和畴态的 重要信息 ${ }^{[25]}$. 实验结果显示(图 5), 所有样品的磁滞 回线线形很细且比较陡直, 在 $300 \mathrm{mT}$ 左右的磁场下 即趋于饱和, 说明样品的磁滞行为是以低矫顽力的 磁性矿物(主要是磁铁矿)为主导.

\section{4 等温剩磁和 $S$ 比值}

等温剩磁获得曲线及其反向场退磁特征是识别 磁性矿物种类的重要参数 ${ }^{[27]}$. 在最大强度为 $2500 \mathrm{mT}$ 连续可变外磁场下获得的等温剩磁曲线表明(图 6(a)),
大多数样品在 $300 \mathrm{mT}$ 左右便已获得饱和等温剩磁的 $90 \%$, 说明样品中剩磁携带者主要是软(易饱和)磁性 矿物居多. 但亚砂土和黄土样品即使用最大场强也 没有达到完全饱和，揭示了其高矫顽力磁性矿物的 存在. 反向磁场退磁结果表明(图 6(b)), 表土样品的 剩磁矫顽力随沉积相带的转换呈明显的规律性变化. 沙漠样品的剩磁矫顽力最低(40 45 mT), 但其饱和 磁化强度却最小, 说明沙漠样品尽管以低矫顽力磁 性矿物为主导，但软磁性矿物的绝对含量并不是很 多. 而亚砂土和黄土样品, 随着海拔的升高, 饱和磁 化强度逐渐减小的同时, 剩磁矫顽力逐渐增大, 由 2100 3300 m 之间的 $50 \mathrm{mT}$ 增加到 $3300 \mathrm{~m}$ 以上的 55 $\mathrm{mT}$, 说明高矫顽力磁性矿物的含量随着海拔的增加 有逐渐增多的趋势. 

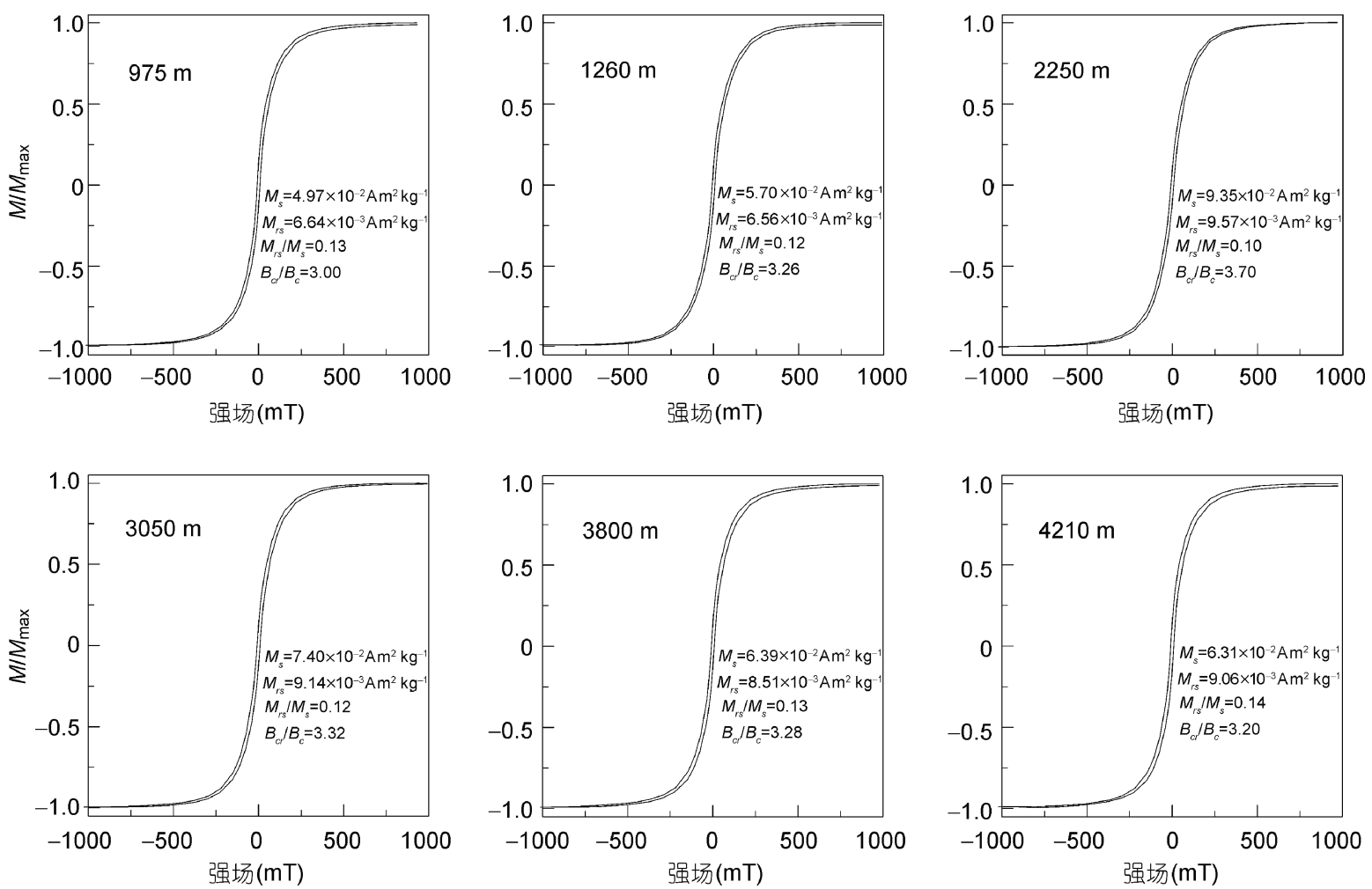

图 5 代表性样品的磁滞回线特征(经过顺磁校正)
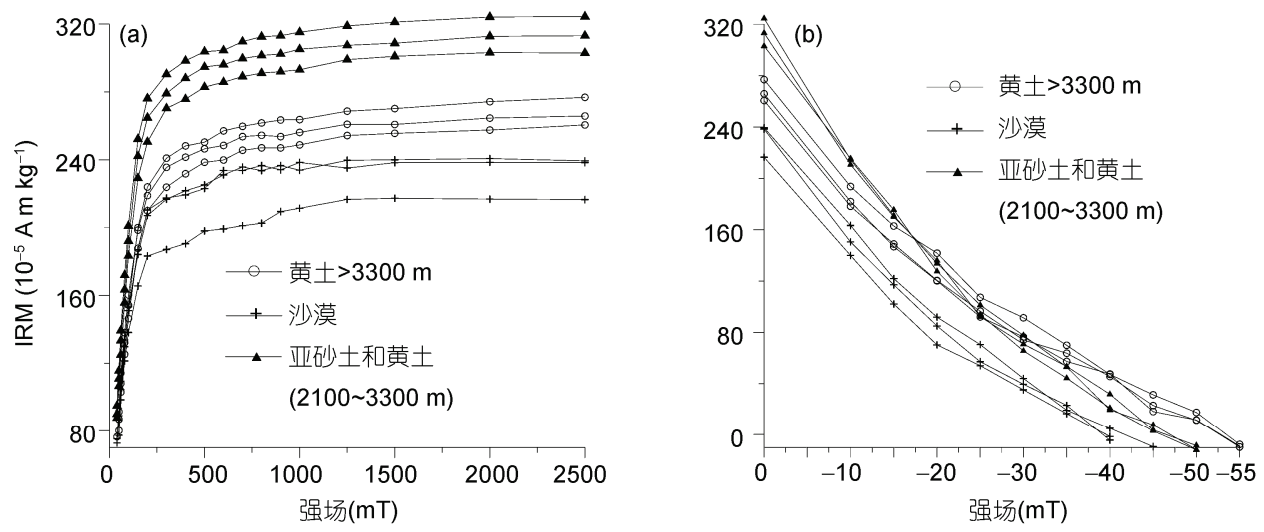

图 6 代表性样品等温剩磁获得曲线(a)和反向磁场退磁曲线(b)

$S$ 比值进一步证实了我们上述的推论(图 2). $S$ 比 值主要反映了样品中低矫顽力磁性矿物 (磁铁矿和磁 赤铁矿)的富集程度 ${ }^{[26]}$. 当样品中低矫顽力磁性矿物 含量较高时, $S$ 比值较高. 随着海拔的升高, 亚砂土 和黄土样品的 $S$ 比值逐渐减小, 说明高矫顽力磁性矿 物的相对含量确实有逐渐增加的趋势. 而沙漠样品 的 $S$ 比值尽管比较高, 但磁化率和饱和等温剩磁却都
为最低值, 反映了主导其磁学性质的软磁性矿物的 浓度很低.

\section{3 讨论}

以上的岩石磁学分析表明, 磁化率和饱和等温 剩磁等磁学参数在沙漠中为最低值, 在黄土和亚砂 土中则随海拔的升高而逐渐减小. 由于海拔的升高, 
不仅会引起气温和降水等气候条件的改变, 而且还 会使粉尘的物质组成在风力分选的作用下产生差异, 因此表土样品磁学性质这种变化很可能是上述两种 因素作用的结果. 不过, 值得强调的是, 这些风尘堆 积的源区以及风场状况是否相同很可能也会对表土 样品的岩石磁学性质有着重要的影响. 但前人对塔 克拉玛干沙漠表土样品所进行的地球化学研究 ${ }^{[28,29]}$, 发现塔克拉玛干沙漠不同地区的矿物组成较为一致, 区域差异极小, 并且对于海拔 $2100 \mathrm{~m}$ 以上的风尘堆 积物质来说, 在强烈的风沙活动作用下, 其在沉积之 前很可能经历了比较强的混合作用, 其代表的应该 是塔克拉玛干沙漠内部各源区的一个平均状况. 因 此我们认为源区以及风场的差异对该区表土样品的 影响应该较小.

\section{1 沙漠样品}

岩石磁学结果表明沙漠样品的磁学性质尽管主 要为软磁性矿物(主要是磁铁矿)所主导(图 4 6), 高 矫顽力磁性矿物的含量很少, 但其磁化率和饱和剩 磁却都显示为最低值, 说明沙漠样品含有的磁铁矿 的浓度很低. 此外, 同亚砂土和黄土样品的平均粒径
与磁化率和饱和等温剩磁都呈很好的正相关关系明 显不同(图 2), 沙漠样品的磁化率和饱和等温剩磁并 没有随着颗粒的变粗而增大, 这说明控制塔里木盆 地风积物表土样品磁学性质的软磁性矿物很可能富 集于一个特殊的粒径区间，而沙漠样品由于在这一 粒径区间的颗粒含量较少致使样品中含有的磁铁矿 浓度很低

前人通过“沉降法”对黄土高原北部一些位于沙

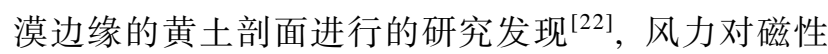
矿物确实有着重要的分选作用, 该区黄土的磁学性 质主要由来自源区的粒径在 31 90 $\mu \mathrm{m}$ 之间的粗颗粒 磁铁矿所控制. 为了进一步探讨研究区表土样品粒 径与磁学性质的关系, 我们对所有表土样品位于 31 90 $\mu \mathrm{m}$ 之间的颗粒百分含量进行了统计, 并做了 相关分析. 结果表明, 表土样品 31 90 $\mu \mathrm{m}$ 之间的颗 粒百分含量随海拔的变化同磁化率十分相似 (图 7(a) 和 3(b)), 并且其与磁化率以及饱和等温剩磁均呈极 高的线性正相关(图 7(b)和(c)), 而其他一些粒径参数 与磁化率则不存在明显的正相关关系(图 8). 以上结 果说明, 主导研究区表土样品磁学性质的软磁性矿 物同样可能富集于 31 90 $\mu \mathrm{m}$ 之间，而沙漠样品的低
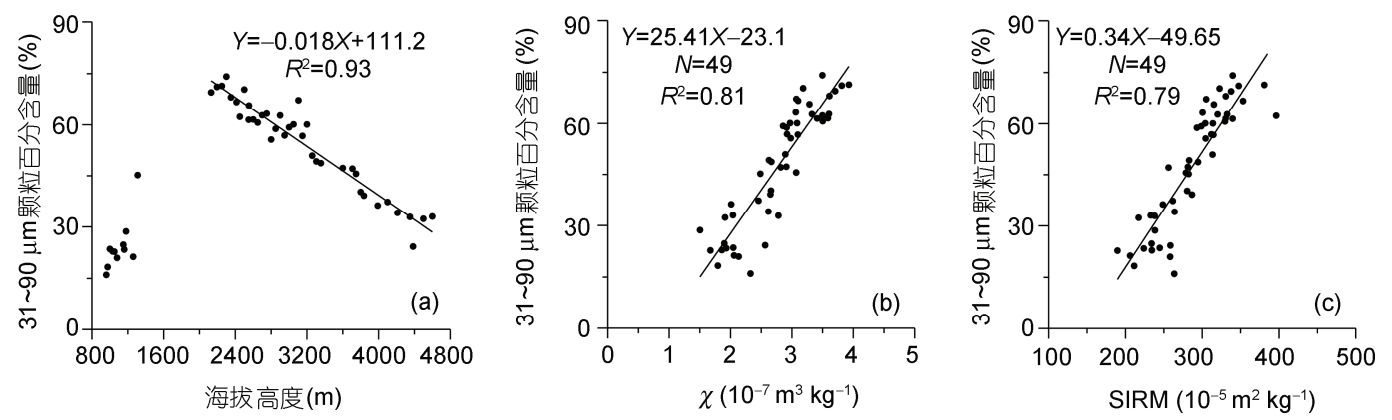

图 7 表土样品 31 90 $\mu \mathrm{m}$ 颗粒百分含量与海拔高度(a)、磁化率(b)以及饱和等温剩磁(c)的相关分析图
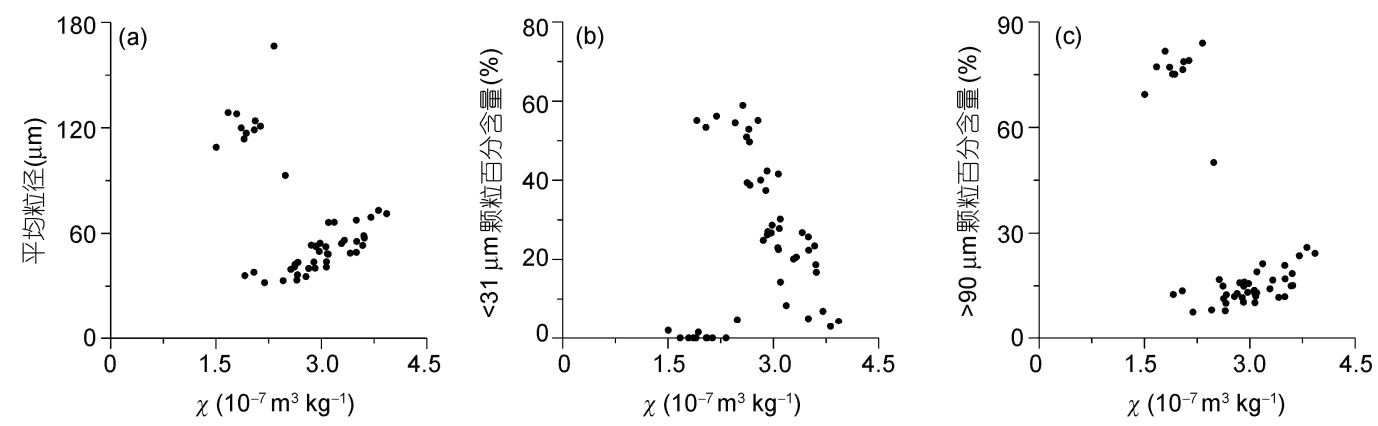

图 8 表土样品平均粒径(a)、 $<31 \mu \mathrm{m}$ 颗粒百分含量(b)以及 $>90 \mu \mathrm{m}$ 颗粒百分含量(c)与磁化率的相关分析图 
磁化率值可能主要是由于风力作用把大量位于 31 90 $\mu \mathrm{m}$ 之间的磁性颗粒吹走所致. 不过由于激光 粒度仪与“沉降法”相比, 两者所获得的不同粒级的 颗粒含量毕竟还存在着一定的差异 ${ }^{[30]}$, 因此这一结 论还需要今后进一步的工作来证实.

\section{2 亚砂土和黄土样品}

亚砂土和黄土样品粒度分析表明, 相对于频率 磁化率与磁化率极弱的相关关系 (图 2), 无论是平均 粒径还是 31 90 $\mu \mathrm{m}$ 之间的颗粒百分含量同磁化率和 饱和等温剩磁均呈很好的线性正相关关系(图 2, 3, 7(b)和(c)), 说明风力分选作用造成的粉尘物质的组 成差异很可能是控制亚砂土和黄土磁学性质的最主 要原因.

但岩石磁学分析同时表明, 气候条件很可能对 高海拔地区的黄土样品的磁学性质也有着一定的影 响. 等温剩磁曲线(图 6)显示 $3300 \mathrm{~m}$ 以上的黄土样品 高矫顽力磁性矿物的含量有了明显的提高, 而且热 磁曲线(图 4)的形态特征(冷却曲线远高于加热曲线, 磁化强度在 $500^{\circ} \mathrm{C}$ 左右有一明显的峰值)同时还表明 有新的弱磁性矿物生成 ${ }^{[17 ~ 20] . ~ L i u ~}$ 等人 $^{[19,20]}$ 最近对西 伯利亚和阿拉斯加黄土的研究认为, 磁性矿物的这 种变化仅用 “风的强度或距离源区的远近” 来解释是 不充分的, 因为它们只会导致磁性矿物物理方面如 数量和粒度大小的变化, 而不应有观察到的化学成 分上的显著不同; 同时, 他们的研究还表明, 当气候 较为湿润、蒸发量较少、地表环境处于一种还原条件 下，热磁曲线的这些特征很可能说明土壤中的磁性 矿物受到了气候条件的影响 ${ }^{[1,20]}$.

而现有的气象资料表明，随着海拔的升高，昆仑 山地区地表环境的确有逐渐向还原条件转变的可能. 李江风等人 ${ }^{[24]}$ 研究表明, 昆仑山地区的年降水递增
率在 $2000 \mathrm{~m}$ 以上为 $18 \mathrm{~mm} / 100 \mathrm{~m}$, 年降水量可以由 $1500 \mathrm{~m}$ 以下的 20 50 $\mathrm{mm}$ 增加到 $3500 \mathrm{~m}$ 以上的 $>400$ $\mathrm{mm}$. 考虑到高海拔地区微弱的蒸发量, 这些降水足 以使地表土壤由于湿润过度而处于一种还原条件下. 因此, 岩石磁学结果揭示的上述磁性矿物的转变, 很 可能暗示昆仑山地区的气候条件在 $3300 \mathrm{~m}$ 左右已经 达到了一个“阈值”, 使表土样品中的磁性矿物在冷 湿的气候条件下发生了明显的变化. 不过，由于目前 证据仍然相对较少, 这还需要今后进一步的工作来 证实.

可见，在塔里木盆地及其周边地区，风尘堆积物 表土的岩石磁学性质主要由来自源区的粗颗粒软磁 性矿物所控制, 成壤作用形成的细颗粒磁性矿物对 其影响较小, 尽管 $3300 \mathrm{~m}$ 以上的表土样品的磁学性 质同样也可能受到了冷湿的气候条件的影响, 但总 体上来说, 研究区表土样品的磁学性质同气候条件 并没有一个固定的规律可循，这也许就是该地区“表 层土壤磁化率随年均气温、年均降水量的变化几乎没 有什么趋势”的原因 ${ }^{[9]}$.

\section{4 结论}

塔里木盆地及其南缘地表沉积物岩石磁学研究 表明, 研究区表土样品的岩石磁学性质主要由来自 源区的粗颗粒软磁性矿物所控制, 成壤作用形成的 细颗粒磁性矿物对其影响非常有限. 其中, 沙漠样品 的磁学性质尽管以磁铁矿为主导, 但磁化率和饱和 等温剩磁都较低, 主要由富集软磁性矿物的 31 90 $\mu \mathrm{m}$ 之间的颗粒含量较少所致. 亚砂土和黄土样品的 各岩石磁学参数 (磁化率以及饱和等温剩磁等)同平 均粒径以及 31 90 $\mu \mathrm{m}$ 之间的颗粒百分含量均呈明显 的正相关关系，表明来自源区的粗颗粒软磁性矿物 的含量是控制样品磁学性质的主要原因.

\section{参考文献}

1 Zhou L P, Oldfield F, Wintle A G, et al. Partly pedogenic origin of magnetic variations in Chinese loess. Nature, 1990, 346: 737-739

2 Maher B A, Thompson R. Mineral magnetic record of the Chinese loess and paleosols. Geology, 1991, 19: 3-6

3 Liu Q S, Banerjee S K, Jackson M, et al. Grain sizes of susceptibility and anhysteretic remanent magnetization carriers in Chinese loess-paleosol sequences. J Geophys Res, 2004, 109: B03101

4 Liu Q S, Jackson M, Banerjee S K, et al. Mechanism of the magnetic susceptibility enhancements of the Chinese loess. J Geophys Res, 2004, 109: B12107

5 邓成龙, 刘青松, 潘永信, 等. 中国黄土环境磁学. 第四纪研究, 2007, 27: 193-209

6 Liu Q S, Deng C L, Torrent J, et al. Review of recent development in mineral magnetism of the Chinese loess. Quat Sci Rev, 2007, 26: 
$368-385$

7 Nie J S, King J W, Fang X M. Enhancement mechanisms of magnetic susceptibility in the Chinese red-clay sequence. Geophys Res Lett, 2007, 34: 19705

8 Nie J, Song Y, King J, et al. Consistent grain size distribution of pedogenic maghemite of surface soils and Miocene loessic soils on the Chinese Loess Plateau. J Quat Sci, 2010, 25: 261-266

9 吕厚远，韩家惁，吴乃琴，等.中国现代土壤磁化率分析及其古气候意义. 中国科学 B 辑, 1994, 24: 1290-1297

10 Maher B A, Thompson R. Paleorainfall reconstructions from pedogenic magnetic susceptibility variations in the Chinese loess and paleosols. Quat Res, 1995, 44: 383-391

11 Maher B A. Magnetic properties of modern soils and Quaternary loessic paleosols: Paleoclimatic implications. Palaeogeogr Palaeoclimatol Palaeoecol, 1998, 137: 25-54

12 Florindo F, Zhu R X, Guo B. Low-field susceptibility and palaeorainfall estimates: New data along a N-S transect of the Chinese Loess Plateau. Phys Chem Earth (A), 1999, 24: 817-821

13 Evans M E, Rokosh C D, Rutter N W. Magnetoclimatology and paleoprecipitation: Evidence from a north-south transect through the Chinese Loess Plateau. Geophys Res Lett, 2002, 29: 1285

14 Bloemendal J, Liu X M. Rock magnetism and geochemistry of two Plio-Pleistocene Chinese loess-palaeosol sequences-Implications for quantitative palaeoprecipitation reconstruction. Palaeogeogr Palaeoclimatol Palaeoecol, 2005, 226: 149-166

15 Begét J E, Stone D B, Hawkins D B. Paleoclimatic forcing of magnetic susceptibility variations in Alaska loess during the late Quaternary. Geology, 1990, 18: 40-43

16 Chlachula J, Evans M E, Rutter N. A magnetic investigation of a late Quaternary loess/palaeosol record in Siberia. Geophys J Int, 1998, 132: $128-132$

17 朱日祥, Kazansky A, Matasova G, 等. 西伯利亚南部黄土沉积物的磁学性质. 科学通报, 2000, 45: 1200-1205

18 Zhu R X, Matasova G, Kazansky A, et al. Rock magnetic record of the last glacial-interglacial cycle from the Kurtak loess section, southern Siberia. Geophys J Int, 2003, 152: 335-343

19 Liu X M, Hesse P, Rolph T, et al. Properties of magnetic mineralogy of Alaskan loess: Evidence for pedogenesis. Quat Int, 1999, 62: 92-102

20 刘秀铭, 刘东生, 夏敦胜, 等. 中国与西伯利亚黄土磁化率古气候记录一一氧化和还原条件下的两种成土模式分析. 中国科学 D辑： 地球科学, 2007, 37: 1382-1391

21 王勇, 潘保田, 管清玉, 等. 西北干旱区黄土-古土壤磁化率变化特征. 海洋地质与第四纪地质, 2008, 28: 111-114

22 Sun J M, Liu T S. Multiple origins and interpretations of the magnetic susceptibility signal in Chinese wind-blown sediments. Earth Planet Sci Lett, 2000, 180: 287-296

23 杨小平. 克里雅河流域风成物质的粒度分析与讨论. 第四纪研究, 1999, 4: 373-379

24 李江风. 新疆气候. 北京: 气象出版社, 1991. 91-124

25 Thompson R, Oldfield F. Environmental Magnetism. London: Allen and Unwin, 1986. 1-227

26 Evans M E, Heller F. Environmental Magnetism: Principles and Applications of Enviromagnetics. New York: Academic Press, 2003

27 Dankers P. Relationship between median destructive field and remanent coercive force for dispersed natural magnetite, titanomagnetite and hematite. Geophys J Res, 1981, 64: 447-461

28 Hattori Y, Suzuki K, Honda M, et al. Re-Os systematics of the Taklimakan Desert sands, moraines and river sediments around the Taklimakan Desert, and of Tibetan soils. Geochim Cosmochim Acta, 2003, 67: 1195-1205

29 Honda M, Shimizu H. Geochemical, mineralogical and sedimentological studies on the Taklimakan Desert sands. Sedimentology, 1998, 45: $1125-1143$

30 Hao Q Z, Oldfield F, Bloemendal J, et al. Particle size separation and evidence for pedogenesis in samples from the Chinese Loess Plateau spanning the last $22 \mathrm{Ma}$. Geology, 2008, 36: 727-730 